\title{
Tari Agirang: \\ Usaha Mengubah Persepsi Masyarakat Bali Terhadap Joged Bumbung
}

Oleh: Putu Merina Rahayu

Jurusan Tari, Fakultas Seni Pertunjukan Institut Seni Indonesia Denpasar

Alamat Email: merinarahayu_putu@yahoo.co.id

\begin{abstract}
RINGKASAN
Agirang merupakan garapan tari kreasi baru yang terinspirasi dari tari Joged Bumbung.. Tari Joged Bumbung merupakan kesenian rakyat populer di Bali yang biasanya dipentaskan pada musim sehabis panen, hari-hari raya, serta hari-hari penting lainnya, dan masih mengandung nilai-nilai moral yang mengangkat tema sosial dalam pengkemasannya

Tujuan diciptakannya karya tari ini yaitu agar dapat mengubah persepsi masyarakat Bali terhadap tari Joged Bumbung yang berkembang saat ini. Joged Bumbung diharapkan tetap memiliki nilai-nilai budaya tinggi yang berfungsi sebagai hiburan bagi masyarakat lokal maupun wisatawan.
\end{abstract}

Kata Kunci: Agirang, Persepsi, Kesenian Joged Bumbung.

\section{ABSTRACT}

Agirang is a new creation of dance creations inspired by Joged Bumbung dance and still contains high moral values that raised the social theme in packaging. Joged Bumbung Dance is a popular folk art in Bali that is usually staged in the aftermath of harvest, feast days, and other important days.

This dance formed to change the perception of Balinese society to Joged Bumbung dance that developed nowdays. Moreover, this dance has cultural values that serve as entertainment for local people and tourists.

Keywords: Agirang, Perception, Joged Bumbung.

\section{PENDAHULUAN}

Akhir-akhir ini, salah satu fenomena yang marak diperbincangkan oleh orang-orang di beberapa jejaring sosial dan di lingkungan masyarakat luas di Bali adalah tari Joged Bumbung. Tarian ini merupakan kesenian 
rakyat populer di Bali yang biasanya dipentaskan pada musim sehabis panen, harihari raya, serta hari-hari penting lainnya.

Seiring perkembangan zaman banyak penari joged yang mulai berani tampil melampaui nilai-nilai etika dan moral yang ada. Joged Bumbung yang terkesan porno belakangan ini banyak beredar di jejaring sosial. Tata saji dan konsep estetik tari Joged Bumbung mulai diabaikan oleh para pelakunya yang membuat jati diri tarian ini menjadi hilang. Hal ini membangunkan kesan bahwa para penari Joged Bumbung tengah melakukan "bunuh diri". Pola-pola gerak tari Joged Bumbung, seperti misalnya menggunakan gerak-gerak tari Bali sederhana, yang tidak di luar batas kewajaran sepertinya telah dikesampingkan.

Fenomena ini dapat dibuktikan dari semakin banyaknya sekaa joged di Bali yang menampilkan tari joged porno di depan umum bersaing ketat demi menarik peminatnya. Sejak beberapa tahun ini dijumpai tampilan "joged porno" dapat disaksikan di jaba pura saat upacara piodalan. Sungguh ironis ketika kita sebagai pelaku seni mendapati kesenian tersebut menjadi racun bagi dirinya sendiri.

Tari Joged Bumbung adalah tari berpasangan laki perempuan yang kadang kala berpegang-pegangan (Dibia, 1979:24). Seperti penjelasan yang ditulis oleh I Wayan Dibia dalam laporan penelitiannya yang berjudul
"Mengenal Beberapa Tari-Tarian Rakyat di Bali” tahun 1979, menguraikan;

"Tari joged mempunyai
banyak macam di antaranya
berupa: Joged Bumbung, Joged
Pingitan, Joged Gebyog, Joged
Pudengan, dan Gandrung. Apabila
di beberapa daerah lain di Bali
terdapat jenis joged lain dari pada
yang disebutkan di sini maka
perbedaan dari pada joged itu
hanyalah terdapat pada masalah
sebutan saja. Ciri khas dari pada
tari joged dengan segala variannya
ini adalah adanya paibing-ibingan
yaitu bagian menari bersama
antara penari joged dengan
penonton yang ditunjuk (dijawat)
oleh penari joged. Lain dari pada
itu bahwa dalam tari joged ini
perlengkapan kipas dapat
dikatakan tidak pernah dilupakan"
(1978:16).

Gerak-gerak dalam tari Joged Bumbung ini menggunakan gerak improvisasi bernuansa erotis yang merangsang para pengibing untuk segera tampil ke atas pentas (Bandem, 1996:63). Gerak-gerak tersebut dilakukan secara spontanitas yang memberikan rangsangan kepada pangibing untuk ikut menari. Ibing-ibingan yang terdapat dalam tari Joged Bumbung, membuat tarian ini lebih hidup dan menarik dibandingkan dengan tari joged lainnya. Adegan ngibing ini banyak memperlihatkan gerakan-gerakan sensual dan goyangan pinggul yang berlebih-lebihan (Bandem,1996:64). Ngibing merupakan bagian terunik dalam sajian tarian yang penuh dengan improvisasi ini. Seperti yang diuraikan di atas, 
JOGED

ISSN: $1858-3989$

goyangan pinggul, senyuman manis, kedipkedipan mata dan gerakan kipas yang menutupi muka penari pertanda sikap malu, merupakan ciri khas dari tari Joged Bumbung yang telah diwariskan sejak zaman lampau (Bandem, 1996:53). I Wayan Dibia menyebutkan tarian ini muncul sekitar tahun 1940 di belahan Bali Utara yang kemudian berkembang dengan cepatnya ke seluruh pelosok pulau Bali (1978:16).

Fenomena Joged Bumbung seperti digambarkan di atas menstimulus penulis untuk memberikan konstribusi kepada masyarakat melalui sebuah karya tari garapan baru untuk menegakkan bahwa tari Joged Bumbung sebenarnya tidak seperti yang berkembang saat ini. Sekaligus memperkenalkan kepada masyarakat bahwa Joged Bumbung itu memiliki pakem yang memberi kesan lincah, energik, demonstratif, erotis, dinamis, dan bukan memiliki daya seksualitas melainkan sensualitas. Menurut Kamus Besar Bahasa Indonesia seksualitas berarti ciri, sifat atau peranan seks; dorongan seks; kehidupan seks, sedangkan sensualitas merupakan segala sesuatu yang mengenai badani bukan rohani. Tarian ini juga memiliki unsur-unsur gerak tari Bali klasik seperti: mungkah lawang, ngumad, nyeledet, nyeleog, nyelier, ngumbang, ngocet, ngegol, nangkis, ngelikas, gelatik mapah dan beberapa gerakan tambahan yang sesuai dengan suasana pajogedan (Dibia, 1978:17).

Berdasarkan latar belakang di atas, ide untuk menggarap karya seni tari ini muncul ketika mendapat rangsangan dari fenomena tari Joged Bumbung yang umumnya banyak diperbincangkan di beberapa jejaring sosial dan khususnya di kalangan masyarakat Bali. Penulis terdorong untuk menciptakan garapan tari kreasi baru dengan mengangkat tema sosial yang berpijak pada tari Joged Bumbung. Penggarapan ini dipicu oleh adanya pola-pola tari joged tersebut yang telah dikesampingkan oleh para penarinya. Menciptakan tari kreasi baru yang bertema sosial dan berpijak dari tari Joged Bumbung sangat membuat penulis bersemangat karena kedekatan penulis dengan Joged Bumbung (sebagai penari).

Garapan ini dimaksudkan untuk memberikan pesan dan kesan serta menyadarkan masyarakat bahwa tari Joged Bumbung merupakan tari pergaulan di kalangan masyarakat Bali yang sifatnya menghibur dengan bercirikan lincah, energik, demonstratif, erotis, dinamis, dan bukan memiliki daya seksualitas melainkan sensualitas. Bukan hanya itu, karya ini juga banyak memberikan unsur kelucuan yang dijumpai pada bagian pangibing-ibingan .

Tari kreasi baru yang berjudul Agirang ini menampilkan enam orang penari yang terdiri dari tiga orang penari putri dan tiga orang 
penari putra. Pertunjukan tari ini berdurasi 12 menit dengan menampilkan estetika, etika dan logika dalam pengkemasannya. Dengan durasi yang telah ditetapkan tersebut penulis berharap karya ini mampu memberikan pesan dan kesan yang berguna dan bermanfaat bagi para apresiator Joged Bumbung. Iringan yang digunakan dalam garapan tari ini mempergunakan gamelan Gagrantangan. Gamelan yang merupakan barungan gamelan tingklik bumbung (potongan-potongan bambu) yang berlaras selendro (Dibia, 1978:17).

Setiap karya seni tentu memiliki tujuan yang ingin disampaikan kepada para apresiator. Begitu juga dengan karya tari kreasi kerakyatan yang berjudul Agirang ini. Tujuan tersebut adalah untuk melatih dan mengembangkan kreativitas yang ada dalam diri penulis, menambah wawasan dalam menggarap tari kreasi yang berpijak pada pola tradisi, untuk membuat karya yang memiliki nilai dan pesan yang dapat berguna bagi masyarakat serta diakui sebagai karya akademik, dan meningkatkan kemampuan dalam berkreativitas untuk menghasilkan karya-karya seni yang inovatif dan dapat diterima di masyarakat. Tujuan khusus dari karya ini yaitu melalui sebuah tari baru, joged inovatif, penulis memperkenalkan tari Agirang yang merupakan pengembangan dari tari Joged Bumbung kepada masyarakat luas, yang dapat memberi pemahaman khususnya kepada masyarakat Bali, bahwa tarian ini memiliki nilai-nilai budaya yang berfungsi sebagai hiburan bagi masyarakat lokal maupun wisatawan. Juga menghilangkan persepsi masyarakat bahwa tarian ini tidak seperti penghibur para lelaki, namun tarian ini dipolakan menjadi bentuk tari Bali yang dikembangkan dan memberikan respon ke penonton untuk menyatukan komunikasi antara penari dengan penonton dalam suasana kegembiraan.

Selain tujuan di atas, terdapat beberapa manfaat dalam pembuatan karya tari ini, yaitu; dapat memberi wawasan dan mengubah persepsi masyarakat terhadap tari Joged Bumbung yang berkembang di masyarakat saat ini, untuk menambah pengalaman dalam berkreativitas di bidang seni tari dari ilmu yang diperoleh baik secara formal maupun non formal, dapat menjadi acuan dalam berkreativitas bagi para seniman, khususnya dalam seni pertunjukan, pesan dan nilai yang disampaikan dapat menjadi cerminan dalam kehidupan bermasyarakat.

\section{PEMBAHASAN}

\section{A. Deskripsi Karya}

Agirang merupakan garapan kreasi baru yang terinspirasi dari tari Joged Bumbung dan masih mengandung nilai-nilai moral tinggi yang mengangkat tema sosial dalam pengkemasannya. Tarian ini ditarikan oleh 6 
(enam) orang penari, 3 (tiga) orang penari putri dan 3 (tiga) orang penari putra yang mempunyai kemampuan menari sesuai dengan keinginan penulis. Menggunakan gerak tari yang lebih energik, lincah dan memberikan kesan sensualitas agar pangibing tertarik untuk mengibing. Keseluruhan garapan ini ingin menyampaikan pesan moral agar persepsi masyarakat terhadap perkembangan joged porno mulai berkurang dan juga memberikan pemahaman terhadap penari joged dan penikmatnya untuk kembali menari sesuai dengan standar pakem tari Bali. Hal ini disebabkan oleh banyaknya perkembangan Joged Bumbung yang keluar dari etika moral masyarakat Hindu Bali, salah satu contoh pengibing yang menggunakan udeng putih saat mengibing penari joged sangat tidak pantas dilihat karena udeng putih biasanya digunakan untuk ke pura memberikan keheningan dalam menghaturkan bakti.

Menghilangkan kesan porno dalam pementasannya adalah hal yang mendasar dari terbentuknya garapan ini karena tari joged pada umumnya merupakan tarian yang sangat populer di masyarakat Bali dan dapat ditampilkan pada wisatawan luar. Melalui garapan tari kreasi baru yang berjudul Agirang pesan-pesan moral yang terkandung diungkapkan melalui bahasa gerak yang diperindah dengan kaidah-kaidah koreografi. Menggunakan desain koreografi, seperti : desain unison (serempak), desain balance (seimbang), desain canon (bergantian), desain alternate (selang-seling) dan desain broken (terpecah) dalam perbendaharaan geraknya (Soedarsono:1975:82). Pendalaman rasa, penghayatan, ekspresi dan penguasaan materi adalah hal yang terpenting untuk mencapai keberhasilan dalam penggarapan karya ini dan tanpa hal itu tari tidak nampak hidup.

Garapan tari kreasi baru ini diberi judul Agirang, menurut Bahasa Jawa Kuno berarti menjadi senang dan bersuka ria dengan durasi pementasan 12 menit. Diiringi oleh gambelan Gagrantangan dengan penata iringan I Kadek Dwi Santika dan dibantu oleh Komang Praptika Kamalia Jaya serta didukung oleh Sekaa Joged Dharma Kanthi, Banjar Selat, Desa Sobangan, Kecamatan Mengwi, Kabupaten Badung.

\section{B. Analisis Pola Struktur}

Struktur karya ini terdiri dari 4 (empat) bagian, yaitu papeson, pangawak, ibingibingan dan pakaad. Kelima bagian tersebut dirangkai sedemikian rupa sehingga mampu menampilkan karya tari yang dapat memberikan gambaran secara utuh dan berkualitas. Struktur tari Agirang ini dapat dijelaskan sebagai berikut:

1. Papeson: menggambarkan tentang paras ayu dari penari joged itu sendiri, 
kelincahan dan sensualitas yang dapat dilihat dari gerak-gerak yang dinamis.

2. Pangawak: menggambarkan tentang penari putri yang sudah mulai melirik pengibing (penari putra), memperlihatkan kecantikan dan lemah gemulai dirinya. Kemudian dilanjutkan dengan tampilnya penari putra memperkenalkan dirinya. Gerak-gerak yang timbul lebih demonstratif, lincah, erotis dan dinamis.

3. Ibing-Ibingan: menggambarkan tentang ibing-ibingan antara penari putri dan putra, dengan suasana gembira dan lucu yang timbul dari gerak-gerak lincah dan demonstratif. Pada bagian ini ada gerakan yang menggambarkan pelarangan terhadap penari joged dan pangibing yang melakukan gerakan porno. Dan juga adanya konflik yang timbul akibat perebutan pangibing antara masingmasing penari joged.

4. Pakaad: menggambarkan tentang akhir dari pertunjukan joged yang memberikan respon ke penonton untuk menyatukan komunikasi antara penari dengan penonton dalam suasana kegembiraan.

\section{Analisis Materi Tari}

Garapan tari kreasi baru Agirang ini menggunakan perbendaharaan gerak-gerak sederhana yang ada dalam suasana pajogedan namun tetap ada pengembangan yang mampu memberikan konstribusi terhadap masyarakat tentang tari Joged Bumbung. Proses penggarapan dalam garapan ini menggunakan materi, yaitu:

1. Desain Koreografi

Garapan tari kreasi Agirang menggunakan 4 desain kelompok dalam penggarapannya, yaitu:

a. Desain unison (serempak) merupakan desain yang lebih banyak mengutamakan kekompakan gerak secara keseluruhan. Desain ini digunakan pada semua bagian garapan, yaitu papeson, pangawak, ibing-ibingan dan pakaad.

b. Desain balance (berimbang), merupakan desain yang membagi posisi penari menjadi dua kelompok secara simetris. Desain ini digunakan pada bagian pangawak dan ibingibingan.

c. Desain canon (bergantian) merupakan desain gerak yang dilakukan secara bergantian 
satu sama lain. Desain ini digunakan pada bagian, papeson, pangawak, dan ibingibingan.

d. Desain alternate (selang-seling) merupakan desain dengan gerakan yang berbeda dalam hitungan yang sama, desain ini digunakan pada bagian pangawak dan ibing-ibingan.

2. Ragam Gerak

Garapan tari kreasi Agirang menggunakan unsur-unsur gerak tari Bali yang merupakan dasar utama dalam menari joged, yaitu:

a. Agem, sikap pokok yang mengandung suatu maksud tertentu, yaitu suatu gerak pokok yang tidak berubah-ubah dari satu sikap pokok ke sikap pokok yang lain.

b. Tandang, cara memindahkan suatu gerakan pokok ke gerakan pokok yang lain, sehingga menjadi satu rangkaian gerak yang saling bersambung.

c. Tangkep, mimik yang memancarkan penjiwaan tari, yaitu suatu ekspresi yang timbul melalui cahaya muka (Djayus:1971:11). d. Tangkis, gerakan penghubung antara gerak satu dengan gerak yang lain.

Motif-motif gerak yang digunakan dalam garapan tari kreasi Agirang ini secara umum dapat diuraikan sebagai berikut:

1. Gerak Kepala: Kipekan (gerakan kepala menoleh ke arah kanan atau kiri dengan patah-patah dipadukan dengan mata melotot), Ngotag (gerakan kepala ke kiri dan ke kanan secara cepat. Bila diteliti pusat gerakan ini ada pada pangkal leher), Nyegut (gerakan dagu yang sedikit dihentakan ke arah bawah, diikuti gerakan mata yang searah dengan gerakan dagu dan kening yang berkerut).

2. Gerak Mata: Nyeledet (gerakan bola mata yang imprensif ke samping kanan dan kiri), Nyelier (gerakan perputaran dagu ke kanan atau ke kiri secara halus, dan diikuti oleh gerakan mata yang dikecilkan atau diredupkan), Nelik (gerakan bola mata yang dibesarkan), Nyerere (gerakan mata ke samping kanan atau kiri).

3. Gerak Tangan dan Badan: Mungkah lawang (keluar dengan membuka tabir atau layar (Dibia:2012:170), Nabdab gelung (gerakan tangan kiri diangkat dan ditekuk ke atas kepala, jari tengah meraba gelungan/hiasan kepala), 
Ngegol (gerakan pinggul ke kanan dan kiri disertai dengan gerakan kepala ke kanan dan ke kiri), Nyeleog (kedua tangan terlentang ke samping bergerak ke bawah seperti nyeluk dan diikuti dengan gerakan badan), Nuding (gerakan tangan menunjuk sesuatu dan juga dipakai untuk melukiskan kemarahan).

4. Gerak Kaki: Ngumbang (gerakan berjalan yang dilakukan dengan badan sedikit merendah (ngaed), levelnya tidak berubah dan disertai dengan gerakan kepala ke kiri dan ke kanan sesuai dengan hentakan kaki), Miles (tumit sebagai tumpuan yang diputar ke kanan atau kiri).

Adapun beberapa gerak yang dikembangkan ke dalam garapan tari kreasi Agirang, yaitu: Agem (posisi badan dalam level rendah, kaki kiri di depan kaki kanan dengan berat badan bertumpu pada kaki kanan. Tangan kanan memegang kipas yang terbuka (ngiluk) dan sejajar dengan kepala, tangan kiri berada di samping kiri dekat pinggul (memegang oncer). Ngegol (posisi badan level rendah, dengan gerakan pinggul ke kanan dan ke kiri dengan permainan tempo patah-patah dan cepat. Ada juga dengan gerakan pinggul ke depan dan ke belakang secara berputar agar meperlihatkan kesan porno). Nabdab gelung (posisi badan level rendah dengan tangan kiri seolah-olah menyentuh gelungan dan tangan kanan berada di samping pinggul (ngukel) disertai goyangan pinggul ke samping kiri). Ngotag (gerakan kepala ke kanan dan ke kiri yang berpusat pada pangkal leher dengan permainan tempo pelan dan cepat). Nyeledet (gerakan bola mata yang imprensif ke samping kanan dan kiri dilakukan dengan permainan tempo pelan dan cepat dan juga dipadukan dengan kedipan mata).

\section{Analisis Simbol}

Garapan tari kreasi baru Agirang memiliki simbol dalam penggarapannya. Suatu karya seni terdapat simbol yang dapat diartikan sebagai sebuah tanda untuk menyampaikan maksud dan tujuan yang ingin disampaikan. Simbol, petanda atau wangsit mempunyai arti tertentu, makna yang luas dari pada apa yang tampil secara nyata, yang dilihat atau didengar (Djelantik,1999:62). Hal ini dapat mempermudah dalam mengungkapkan gagasan dan ide dari garapan tari kreasi baru Agirang.

Tari kreasi Agirang memiliki simbol dalam perbendaharan gerak dan warna kostum yang digunakan. Simbol-simbol yang ditampilkan bertujuan agar pesan yang disampaikan dapat secara langsung diterima oleh penonton selain itu dapat menimbulkan unsur keindahan dalam karya itu sendiri. 
JOGED

ISSN: $1858-3989$
Putu Merina Rahayu (JURNAL Tari Agirang: Usaha Mengubah Persepsi Masyarakat Bali Terhadap Joged Bumbung)
Simbol dalam perbendaharaan gerak tersebut diambil dari gerak-gerak tari tradisi yang dikembangkan dan masih berpola gerakgerak pajogedan seperti halnya gerakan mungkah lawang, agem, nyeledet,nabdab gelung dan ngegol kemudian diolah kembali sehingga menjadi ciri khas gerak dari karya tari kreasi ini. Hal tersebut digunakan untuk melambangkan kelincahan, erotis, demonstrativ dalam menari joged dan yang paling penting memberikan daya tarik untuk pangibing. Gerakan yang digunakan pangibing lebih bebas dengan beberapa simbol gerak seperti contoh, gerak lincah, demonstratif, lucu yang melambangkan ketertarikan terhadap penari joged. Ekpresi seperti contoh senyum (makenyem) dan lirikan mata sangat berperan penting dalam penari joged karena dapat memberikan ketertarikan pengibing untuk menari bersama.

Simbol warna dalam tari kreasi Agirang ini terdapat pada perpaduan warna yang digunakan dalam kostum, seperti warna kuning yang dapat memberikan kesan monyer, warna merah muda memberikan kesan agar pengibing menjadi tertarik untuk mengibing dan warna ungu memberikan kesan keagungan untuk penari joged itu sendiri.

\section{E. Analisis Penyajian}

Garapan tari kreasi Agirang ini disajikan dalam durasi 12 menit ke dalam bentuk tari kelompok yang ditarikan 6 (enam) orang penari, 3 (tiga) penari putri dan 3 (tiga) penari putra. Mengangkat tari joged sebagai pijakan penulis yang dimaksudkan agar tidak berkembang pesat tari joged porno. Dalam pementasan karya ini dilengkapi dengan tata lampu, pola lantai, musik iringan dan kostum untuk memperkuat kualitas garapan tari Agirang.

Menghilangkan kesan porno dalam pementasannya adalah hal yang mendasar dari terbentuknya garapan ini karena tari joged pada umumnya merupakan tarian yang sangat populer di masyarakat Bali dan dapat ditampilkan pada wisatawan luar. Melalui garapan tari kreasi baru yang berjudul Agirang dikemas dengan pada awal tarian dimulai (papeson) menampilkan 3 orang penari putri yang gerak-gerak tarinya dikombinasi sesuai kaidah-kaidah koreografi dan juga permainan pola lantai sebagai bentuk sajian baru dari tari joged pada umumnya dan juga didukung 3 orang penari putra sebagai pangibing.

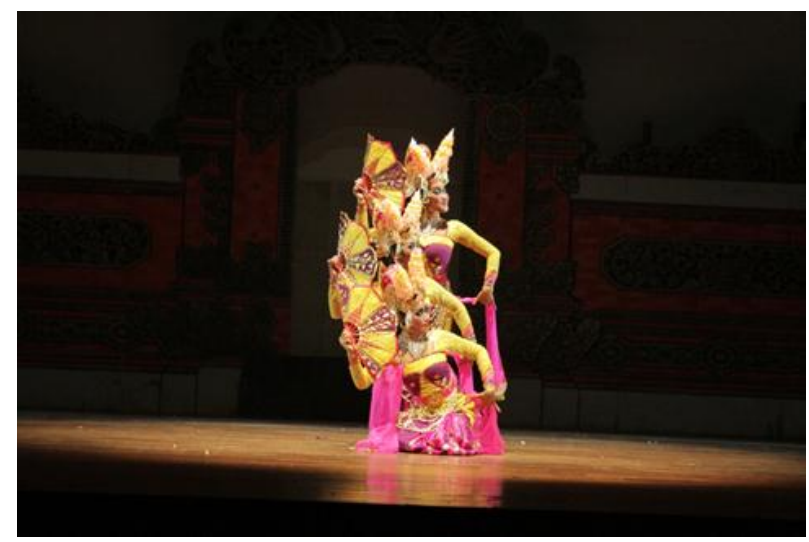

Foto Papeson Dokumentasi Kadek Purnadioga 


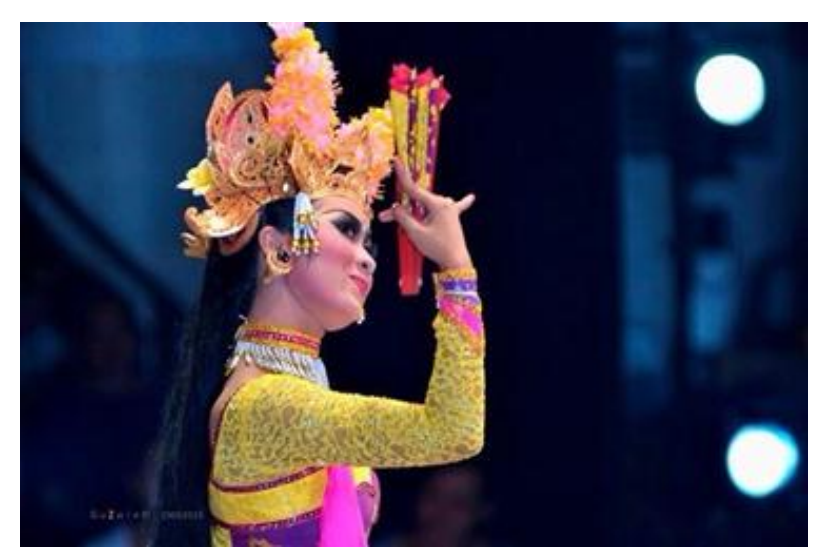

Foto Papeson

Dokumentasi Kadek Purnadioga

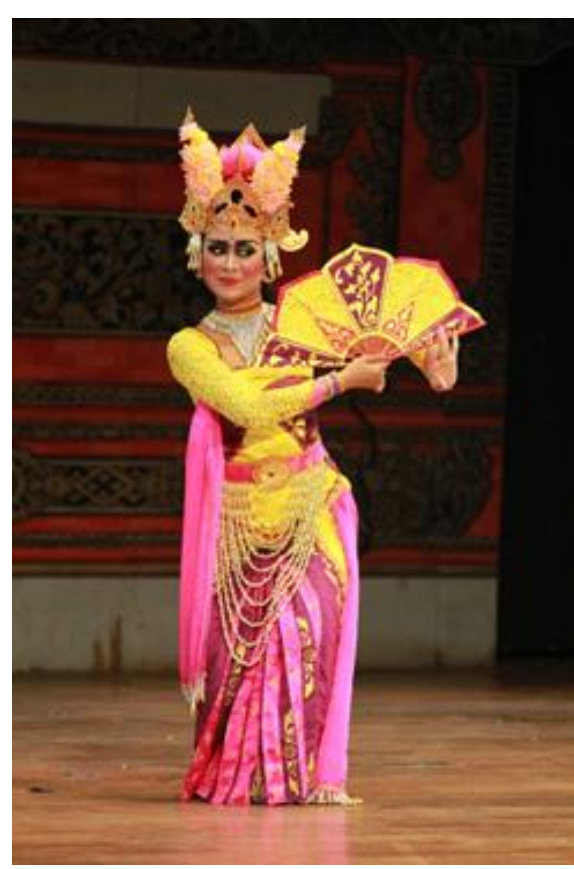

Foto Papeson

Dokumentasi Kadek Purnadioga

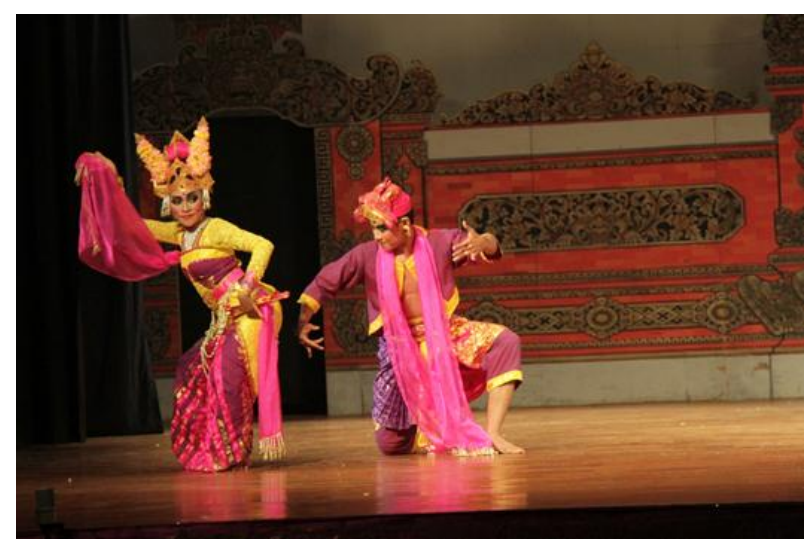

Foto Ibing-ibingan

Dokumentasi Kadek Purnadioga

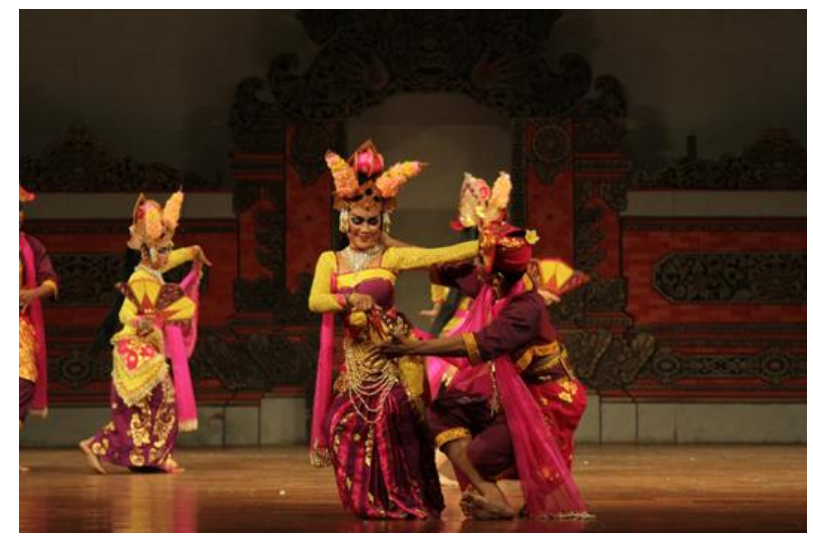

Foto Ibing-ibingan

Dokumentasi Kadek Purnadioga

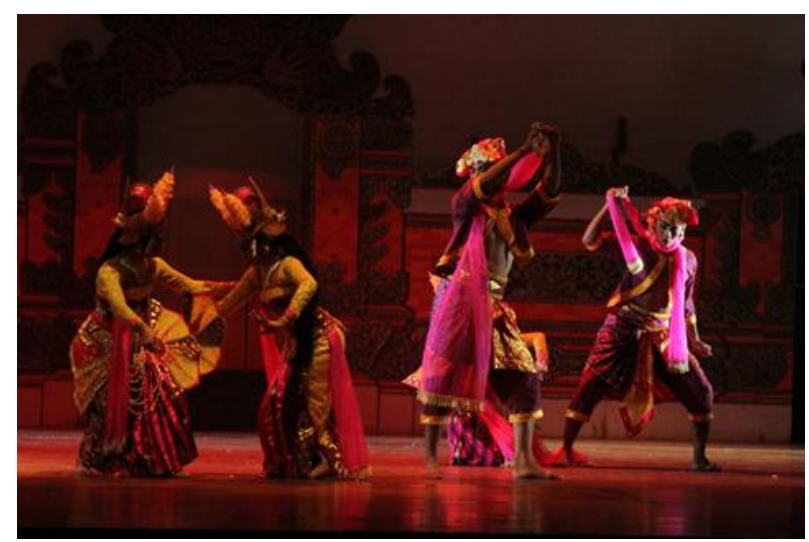

Foto Ibing-ibingan (adegan ngambul)

Dokumentasi Kadek Purnadioga

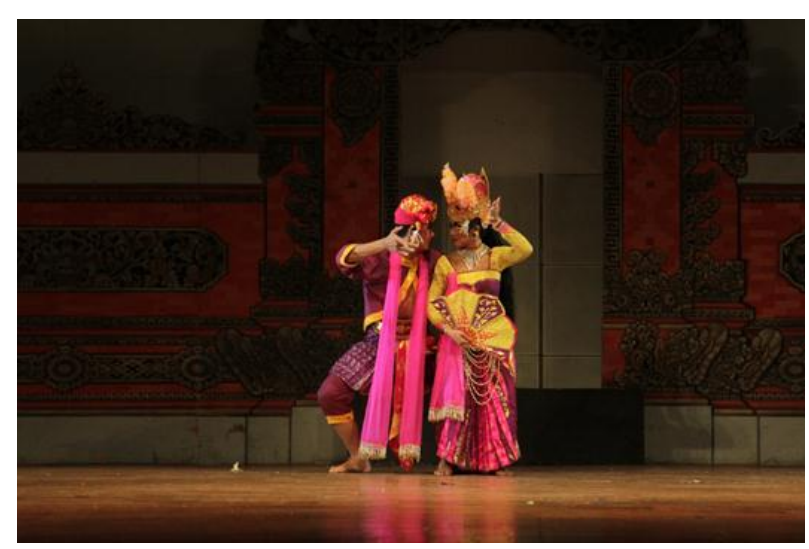

Foto Pakaad

Dokumentasi Kadek Purnadioga

\section{F. Kostum atau Tata Busana}

Kostum atau tata busana merupakan unsur yang menunjang garapan ini dan berfungsi 


\section{JOGED}

ISSN: $1858-3989$

sebagai penutup organ tubuh sekaligus memperindah penampilan. Mampu memberikan komunikasi ke penonton tentang arti, isi atau warna dari karakter yang diangkat sesuai dengan ide cerita garapan. Hal ini dapat memberikan nilai tersendiri terhadap keutuhan dari setiap garapan. Kostum yang digunakan dalam tari kreasi Agirang ini masih berpedoman pada tari joged pada umumnya, dengan memakai bancangan, kipas, oncer yang merupakan ciri khas dari joged. Memadukan penggunaan ankin dan kebaya dalam kostum tarian ini karena tari joged yang berkembang dari tahun 1940 berbeda ada yang menggunakan kebaya ataupun ankin. Berpijak dari hal tersebut, maka terwujudlah desain kostum yang sederhana untuk memberikan ketegasan dalam garapan dan tidak mengganggu gerak-gerak tari yang dilakukan.

\section{G. Tata Rias Wajah}

Tata rias wajah dalam sebuah penyajian karya tari adalah hal yang penting dalam menunjang garapan ini agar sesuai dengan karakter yang dibawakan. Menggunakan tata rias putri alus untuk penari joged dan rias putra alus untuk pengibing. Adapun perlengkapan yang digunakan dalam tata rias garapan tari Agirang adalah menggunakan tata rias panggung sebagai berikut:
1. Milk cleansing, untuk membersihkan wajah yang dapat mengangkat kotoran yang menempel di wajah.

2. Face tonic, untuk menyegarkan wajah.

3. Alas bedak padat berwarna coklat krayolan 4W, berfungsi sebagai foundation wajah sehingga pori-pori wajah tertutupi dan bedak tabur dapat melekat dengan baik.

4. Bedak tabur merah Viva 05, digunakan setelah alas bedak untuk melapisi foundation sehingga dapat meratakan wajah dengan baik.

5. Pensil alis hitam, untuk mempertegas bentuk alis, dan juga digunakan membuat caling kidang.

6. Eye shadow, digunakan pada hidung (berwarna coklat) untuk mempertegas garis hidung, pada kelopak mata (berwarna kuning, merah, biru, coklat dan hitam) untuk memberi aksen pada mata sehingga kelihatan lebih hidup.

7. Merah pipi, untuk mempertegas tulang pipi.

8. Eye liner cair, untuk mempertegas alis dan digunakan pada garis mata atas dan bawah agar terlihat lebih tajam.

9. Lipstik merah, untuk membuat bibir terlihat lebih indah dan mencegah kekeringan pada bibir. 
10. Vinilex putih, untuk membuat gecek atau titik yang diletakkan di atas alis dan di kedua pelipis.

\section{H. Properti}

Properti yang digunakan pada tari kreasi Agirang ini adalah kipas yang tak lain merupakan ciri khas dari tari joged. Kipas ini berwarna ungu gradasi, kuning dan merah muda yang merupakan perpaduan dari kostum penari. Penggunaan warna dan imbuhan prada membuat kipas itu terlihat lebih menarik.

\section{Musik Iringan}

Musik iringan menjadi pendukung yang terpenting dalam menyajikan garapan ini. Tari memang memiliki dinamika namun dalam tari dapat diperkuat dengan permainan ritme dan tempo yang terdapat pada musik iringan sehingga antara tari dengan musik dapat berjalan selaras. Di samping itu juga musik iringan dapat menimbulkan kesan yang kuat untuk menghidupkan suasana pajogedan.

Tari kreasi Agirang menggunakan gamelan Gagrantangan yang merupakan barungan gamelan tingklik bumbung (potongan-potongan bambu) yang berlaras selendro (Dibia, 1978:17). Dipilihnya gamelan tersebut didasari atas pertimbangan bahwa suara yang dihasilkan mampu memberikan kesan yang kuat untuk menghidupkan suasana pajogedan. Penata karawitan yaitu I Kadek
Dwi Santika dan dibantu oleh Komang Praptika Kamalia Jaya. Adapun pendukung karawitan Sekaa Joged Dharma Kanthi, Br. Selat, Desa Sobangan, Kecamatan Mengwi, Kabupaten Badung. Beberapa alat dari gamelan Gagrantangan yang digunakan pada garapan tari kreasi ini, yaitu: dua buah rindik, satu buah kendang, satu buah gong pulu, satu buah suling, satu buah kemong, satu buah klenang, satu buah jegog, satu buah ceng-ceng ricik dan satu buah tawa-tawa.

\section{KESIMPULAN}

Tari Agirang adalah garapan baru yang berpijak pada tari Joged Bumbung dan masih mengandung nilai-nilai moral dengan mengangkat tema sosial dalam pengkemasannya. Melalui sebuah tari baru, joged inovatif, penata memperkenalkan tari Agirang yang merupakan pengembangan dari tari Joged Bumbung kepada masyarakat luas, yang dapat memberi pemahaman khususnya kepada masyarakat Bali, bahwa tarian ini memiliki nilai-nilai budaya yang berfungsi sebagai hiburan bagi masyarakat lokal maupun wisatawan. Juga menghilangkan persepsi masyarakat bahwa tarian ini tidak seperti penghibur para lelaki, namun tarian ini dipolakan menjadi bentuk tari Bali yang dikembangkan dan memberikan respon ke penonton untuk menyatukan komunikasi 
antara penari dengan penonton dalam suasana kegembiraan.

Sinonim tari adalah joged berarti joged merupakan luapan ekspresi yang diungkapkan sebebas mungkin sesuai dengan situasi dan kondisi. Maka dari hal itu joged adalah tarian yang dilakukan secara spontanitas bersumber dari gerak-gerak yang demonstratif, lincah yang memberikan gambaran suka, riang dan gembira dalam menari dan gerak-gerak yang timbul dapat merangsang penonton untuk ikut di dalamnya.

\section{DAFTAR SUMBER ACUAN}

A. Sumber Tercetak

Bandem, I Made. 1996. Evolusi Tari Bali. Denpasar: Kanisius.

Dibia, I Wayan, 1978/1979. “Mengenal Beberapa Tari-Tarian Rakyat Di Bali”. Denpasar: Proyek Pengembangan Institut Kesenian Indonesia Jakarta Sub/Bagian Proyek ASTI Denpasar.

— 2012. Mongkah Tanah
Mungkah Lawang Biografi Seniman I Wayan Geria. Denpasar: Yayasan Wayan Geria. , 1979. Sinopsis Tari Bali. Sanggar Tari Bali “Waturenggong” Denpasar.
Djayus, Nyoman, 1971. Teori Tari Bali. Denpasar.

Djelantik, Dr. A.A.M, 1990. Pengantar Dasar Ilmu Estetika Jilid I Estetika Instrumental. Denpasar: STSI Denpasar.

Wibowo, Fred.1913. Mengenal Tari Klasik Yogyakarta. Yogyakarta: Dewan Kesenian Provinsi DIY.

Hawkins, Alma M, 1988. Creating Through Dance, diterjemahkan Y. Sumandiyo Hadi berjudul Mencipta Lewat Tari (2003). Yogyakarta: Manthili. , 1988. Moving From Within:

A New Method for Dance Making, diterjemahkan I Wayan Dibia berjudul Bergerak Menurut Kata Hati: Metode Baru Dalam Menciptakan Tari (2003). Jakarta: MSPI.

Hutchinson, Ann. 1977. Labanotation The System of Analyzing and Recording Movement. New York.

Soedarsono.1975. Komposisi Tari Elemen-Elemen Dasar, (Terjemahan dari Dance Composition the Basic Elemen oleh La Meri). Yogyakarta. 
Putu Merina Rahayu (JURNAL Tari Agirang: Usaha Mengubah Persepsi Masyarakat Bali Terhadap Joged Bumbung)

JOGED

ISSN: 1858-3989 